\title{
Characterizing Adsorption of Associating Surfactants on Carbonates Surfaces
}

\author{
Guoqing Jian, Maura Puerto, Anna Wehowsky \\ Clarence Miller, George J. Hirasaki* and Sibani L. Biswal*, \\ Department of Chemical and Biomolecular Engineering, Rice University
}

\section{Abstract \\ Hypothesis}

The adsorption of anionic surfactants onto positively charged carbonate minerals is typically high due to electrostatic interactions. By blending anionic surfactants with cationic or zwitterionic surfactants, which naturally form surfactant complexes, surfactant adsorption is expected to be influenced by a competition between surfactant complexes and surfactant-surface interactions.

\section{Experiments}

The adsorption behavior of surfactant blends known to form complexes was investigated. The surfactants probed include an anionic $\mathrm{C}_{15-18}$ internal olefin sulfonate (IOS), a zwitterionic lauryl betaine (LB), and an anionic $\mathrm{C}_{13}$-alcohol polyethylene glycol ether carboxylic acid (L38). An analytical method based on high-performance liquid chromatography evaporative light scattering detector (HPLC-ELSD) was developed to measure three individual surfactant concentrations from a blended surfactant solution. The adsorption of the individual surfactants and surfactant blends were systematically investigated on different mineral surfaces using varying brine solutions.

\section{Findings}

LB adsorption on calcite surfaces was found to be significantly increased when blended with IOS or L38 since it forms surfactant complexes that partition to the surface. However, the total adsorption of the LB-IOS-L38 solution on dolomite decreased from $3.09 \mathrm{mg} / \mathrm{m}^{2}$ to $1.97 \mathrm{mg} / \mathrm{m}^{2}$ when blended together compared to single surfactant adsorption, which is beneficial for applications such as enhanced oil recovery.

Keyword: adsorption, HPLC_ELSD, surfactant, surfactant complexes, carbonate

*To whom correspondence should be addressed: email: biswal@rice.edu and gjh@rice.edu 


\section{Introduction}

Surfactants[1-2] have been widely used in enhanced oil recovery (EOR) processes due to their ability to decrease the oil/water interfacial tension[3-4] and facilitate the generation of foam[5-6] [7], and this ability has been widely studied and applied in various field tests[8-9]. Surfactant adsorption[10-12] onto mineral surfaces is one of the most important issues to address for chemical EOR. Furthermore, it is critical to understand the adsorption mechanism for a target reservoir[13]. Recent studies have shown that blending surfactants with different ion types, such as cationic and anionic[14], anionic and nonionic[15-17], or anionic and zwitterionic[18], can facilitate and enhance the performance of the surfactant system. Internal olefin sulfonate is a commercialized anionic surfactant for EOR, and it has the potential to be used in foam mobility control[19] and low-tension gas flooding[20]. However, due to the high hydrophobicity of internal olefin sulfonate (IOS) molecules, IOS is difficult to dissolve in high salinity brine. Anionic surfactants, with EO groups in their hydrophilic head[18], can improve the solubility of IOS in high salinity brine, which extends the applications of IOS. We have recently shown that lauryl betaine (LB), a zwitterionic surfactant, and $\mathrm{C}_{13}$-alcohol polyethylene glycol ether carboxylic acid (L38), an anionic surfactant, increase the foamability of an IOS solution in the presence of crude oil[18] [21]. These blended surfactant systems can decrease the oil/water interfacial tension and generate foam, illustrating their potential in low-tension gas/foam flooding. However, the adsorption behavior of these surfactant systems has not been systematically studied, which limits the understanding of the transport and interfacial phenomena in these processes.

Here, an optimized HPLC-ELSD [22-26] method was successfully developed for the analysis of complex multicomponent surfactant formulations that cannot be analyzed by conventional titration methods due to their interactions. Second, the adsorption of each component and surfactant blend was systematically studied on differently charged mineral surfaces. Surfactant degradation under aerobic conditions was found to take place and application of sodium sulfite was successful in solving this issue. The adsorption mechanisms of multicomponent surfactant formulations on charged surfaces are discussed.

\section{Materials and methods}

\subsection{Materials}


Water and acetonitrile (Sigma-Aldrich, HPLC grade) were used as received for HPLC analyses. Sodium chloride $(\mathrm{NaCl}$, certified ACS, Sigma Aldrich), potassium chloride ( $\mathrm{KCl}$, certified ACS, Sigma Aldrich), calcium chloride dihydrate $\left(\mathrm{CaCl}_{2} \cdot 2 \mathrm{H}_{2} \mathrm{O}\right.$, certified GR ACS grade, EMD Chemicals), magnesium chloride hexahydrate $\left(\mathrm{MgCl}_{2} \cdot 6 \mathrm{H}_{2} \mathrm{O}\right.$ certified GR ACS grade, EMD Chemicals) and sodium sulfite $\left(\mathrm{Na}_{2} \mathrm{SO}_{3}\right.$, certified ACS, Sigma-Aldrich) were used as received. Deionized water $(18.2 \mathrm{M} \Omega \cdot \mathrm{cm})$ was used to prepare all the surfactant solutions. The other minerals studied included ScienceLab dolomite $(\leq 74 \mu \mathrm{m}$, ScienceLab Inc., Catalog \#SLD4477), calcite $(\leq$ $5 \mu \mathrm{m}$, Alfa Aesar, Catalog \#11403), silica (<10 $\mu \mathrm{m}$, U.S. silica) and kaolin (0.1 4 $\mu \mathrm{m}$, Sigma Aldrich, Catalog \#K7375).

\subsection{Surfactant Solutions}

Three surfactants (Lauryl betaine: from Solvay; 30.7\% activity. Lot\#110403, $\mathrm{M}_{\mathrm{LB}}=271 \mathrm{~g} / \mathrm{mol}$; $\mathrm{C}_{15 \text { - }}$ ${ }_{18} \mathrm{IOS}$ from Shell; Enordet0332, LR\#28253-49; activity 27.99\%, $\mathrm{M}_{\mathrm{IOS}}=345 \mathrm{~g} / \mathrm{mol}$; L38 from Sasol Germany; $\mathrm{C}_{13}$-alcohol polyethylene glycol ether carboxylic acid; CAS\#68412-55-5; 90\% activity, $\mathrm{M}_{\mathrm{L} 38}=391 \mathrm{~g} / \mathrm{mol}$ ) were used without further purification. The solutions studied for the individual components were DI water at $80^{\circ} \mathrm{C}$, DI water at $20^{\circ} \mathrm{C}, 10 \mathrm{wt} \% \mathrm{NaCl}$ brine at $20^{\circ} \mathrm{C}$, and $5 \mathrm{wt} \%$ $\mathrm{CaCl}_{2}$ at $20^{\circ} \mathrm{C}$. Our previous results successfully utilized a surfactant blend of $0.6 \mathrm{wt} . \%$ IOS +

0.4 wt. \% LB +0.1 wt. \% L38 to achieve ultra-low interfacial tension, which increased oil recovery in carbonate minerals[18] [21]. Individual surfactant solutions were initially prepared in DI water and titrated to $\mathrm{pH}=7.0 \pm 0.2$ by either $1 \mathrm{M}$ hydrochloric acid or $0.1 \mathrm{M}$ sodium hydroxide. The solutions are then blended to the target concentration. For solutions prepared in brine, care must be taken to prevent surfactant precipitation. 


\subsection{Properties of minerals}

Energy dispersive X-ray (EDX) (FEI Quanta 400 ESEM FEG) spectroscopy was employed for determining the surface composition of the minerals. From the elemental composition analysis of the different materials tested, it could be seen that the dolomite mainly consists of elements such as calcium and magnesium, with small amounts of aluminum and silicon. The calcite used consists of calcium with trace amounts of magnesium. Kaolin mainly consists of aluminum and silica, which is typical of clays. Silica powder was also tested as a standard to compare maximum adsorption of IOS.

The Brunauer-Emmett-Teller surface areas of the adsorbents were measured with a surface analyzer based on nitrogen adsorption (Quantachrome instruments Autosorb-3B). The samples were dried at $200^{\circ} \mathrm{C}$ at a pressure below 20 mTorr for more than 12 hours. The temperature of the liquid nitrogen bath used during the BET test was kept at $77.4 \mathrm{~K}$. The reported multipoint BET surface area resulted from 11 points in the adsorption isotherm. The correlation coefficient for the measurement was higher than 0.99 .

Table 1 Properties of the minerals used

\begin{tabular}{|l|l|l|l|l|l|l|}
\hline \multirow{2}{*}{ Minerals } & \multicolumn{3}{|l|}{ Mass ratio of the main elements $(\mathrm{wt} \%)$} & \multicolumn{2}{l}{$\begin{array}{l}\text { Zeta potential(mV) in } \\
0.1 \mathrm{M} \mathrm{NaCl}\end{array}$} & $\begin{array}{l}\text { BET surface } \\
\text { area } \\
\left(\mathrm{m}^{2} / \mathrm{g}\right)\end{array}$ \\
\cline { 2 - 7 } & $\mathrm{Ca}$ & $\mathrm{Mg}$ & $\mathrm{Al}$ & $\mathrm{Si}$ & & \\
\hline Calcite & $33.39 \pm 6.53$ & $0.84 \pm 0.55$ & 0.00 & 0.00 & $4.4 \pm 0.7(\mathrm{pH}=9.71)$ & 2.12 \\
\hline Dolomite & $14.48 \pm 2.73$ & $12.41 \pm 3.81$ & $0.95 \pm 0.47$ & $2.10 \pm 1.56$ & $3.5 \pm 0.4(\mathrm{pH}=9.78)$ & 0.85 \\
\hline Silica & 0.00 & 0.00 & 0.00 & $46.67 \pm 1.95$ & $-34.5 \pm 2.5(\mathrm{pH}=6.27)$ & 4.01 \\
\hline Kaolin & 0.00 & 0.00 & $21.79 \pm 1.43$ & $23.65 \pm 1.83$ & $-12.9 \pm 0.9(\mathrm{pH}=3.95)$ & 18.63 \\
\hline
\end{tabular}

The zeta potentials of the four representative minerals were tested in $0.1 \mathrm{M} \mathrm{NaCl}$ solution. The zeta potentials of the dolomite and calcite were found to be positive, and the values for silica and kaolin were negative.

\subsection{High-Performance Liquid Chromatography (HPLC)}

The surfactants tested in this study are a mixture of two anionic and one zwitterionic surfactant. Either of the anionic surfactants can complex with the zwitterionic surfactant, which made it difficult to analyze the surfactant concentration by titration methods. To solve this problem, an 
HPLC-ELSD method was developed to separate each surfactant in a surfactant blend. An ELSD detector (Agilent 1200 Series Technologies ELSD) was used to determine the surfactant concentration. The mobile phase consisted of $100 \mathrm{mM}$ ammonium acetate (catalog\# 431311, Sigma-Aldrich, $\geq 99.99 \%$ tracer metals basis) or ammonium formate (catalog\# 17843, Fluka, $\geq 99.0 \%$ HPLC grade), and the $\mathrm{pH}$ was adjusted with either acetic acid (catalog \#338826 sigma Aldrich; $\geq 99.99 \%$ tracer metals basis) or formic acid(catalog\# 94318, Fluka, $\geq 98 \%$ ) in HPLC water. The column was a Dionex Acclaim surfactant column, 4.6*250 mm (Product No. 063203). The flow rate of the total mobile phase was $1 \mathrm{~mL} / \mathrm{min}$. The measurements were made at $60^{\circ} \mathrm{C}$, and the injection pressure of the carrier gas $\mathrm{N}_{2}$ was kept at 3.5 bars. The volume of the sample injection for all experiments was $50 \mu \mathrm{L}$.

First, the surfactant was tested using a surfactant column. As shown in Figure 1, when the pH of the buffer solution (ammonium acetate/acetic acid) equals 5.5, the signal of LB overlaps with the signal of $\mathrm{C}_{15-18} \mathrm{IOS}$ and the main peak of L38. To differentiate the molecules, the buffer solution was changed to an ammonium formate/formic acid $(\mathrm{pH}=3.0)$ solution, which protonates the betaine. At low pH values, L38 acts as a nonionic surfactant form because it is a weak acid. As shown in Figure 1(b), when the $\mathrm{pH}$ of the solution was changed to 3.0, the signals of LB and IOS could be well separated. The signal of L38 was in between the signals from LB and IOS. 


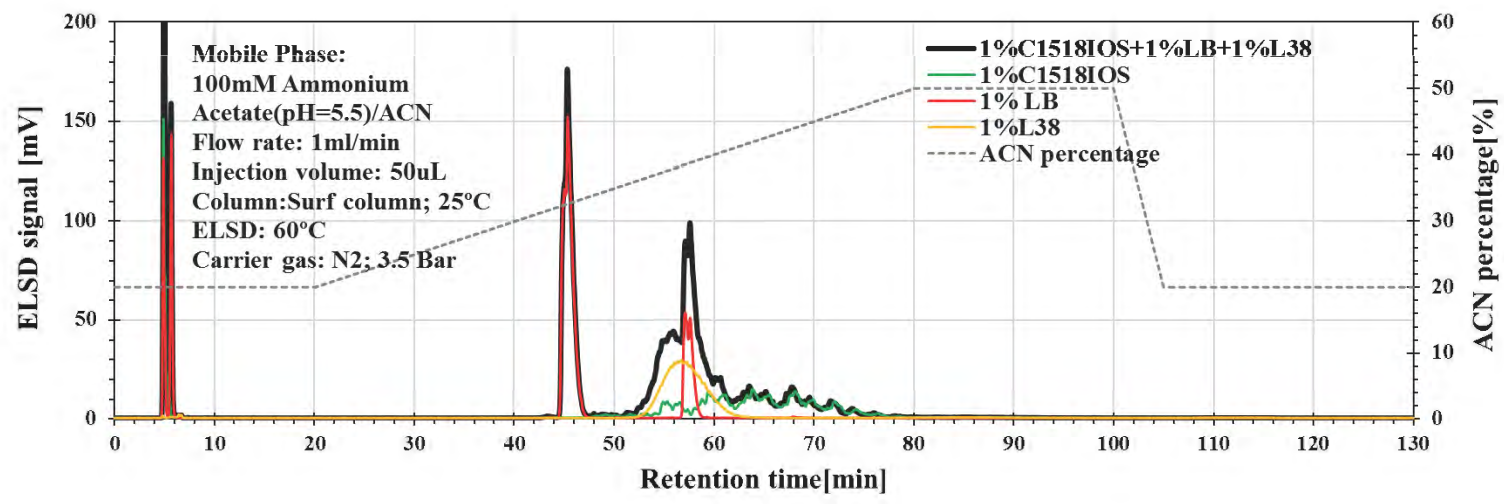

(a)

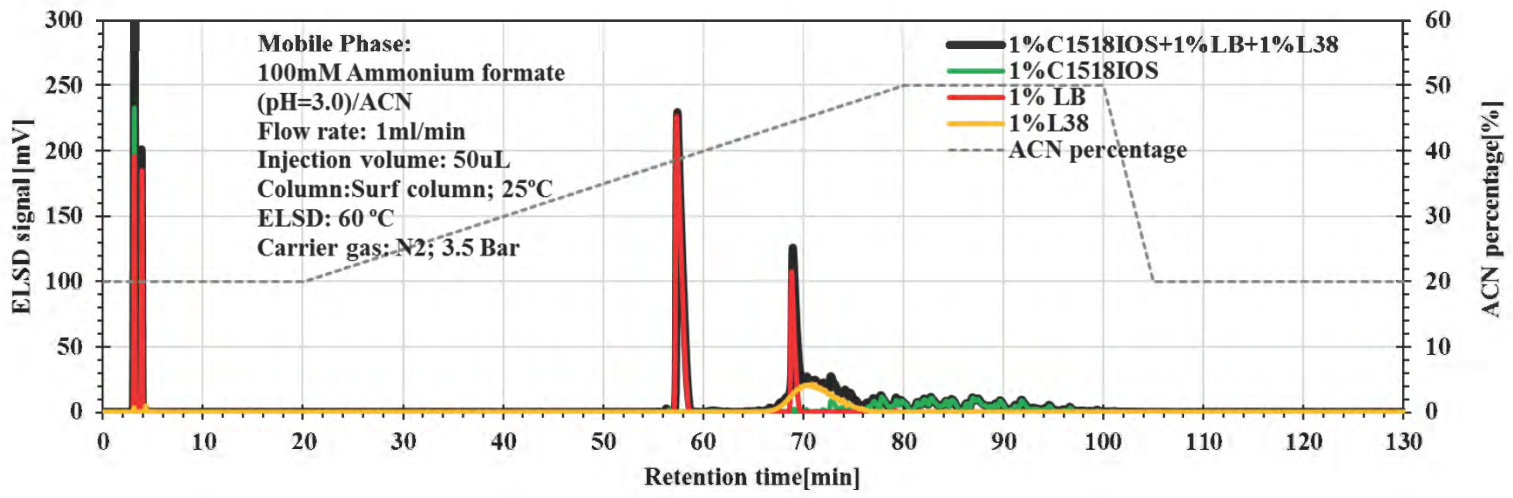

(b)

Figure 1. HPLC-ELSD method development for detection of surfactant blends using aqueous buffer solutions (a) ammonium acetate/acetic acid, $\mathrm{pH}$ 5.5. (b) ammonium formate/formic acid, $\mathrm{pH} 3.0$. 


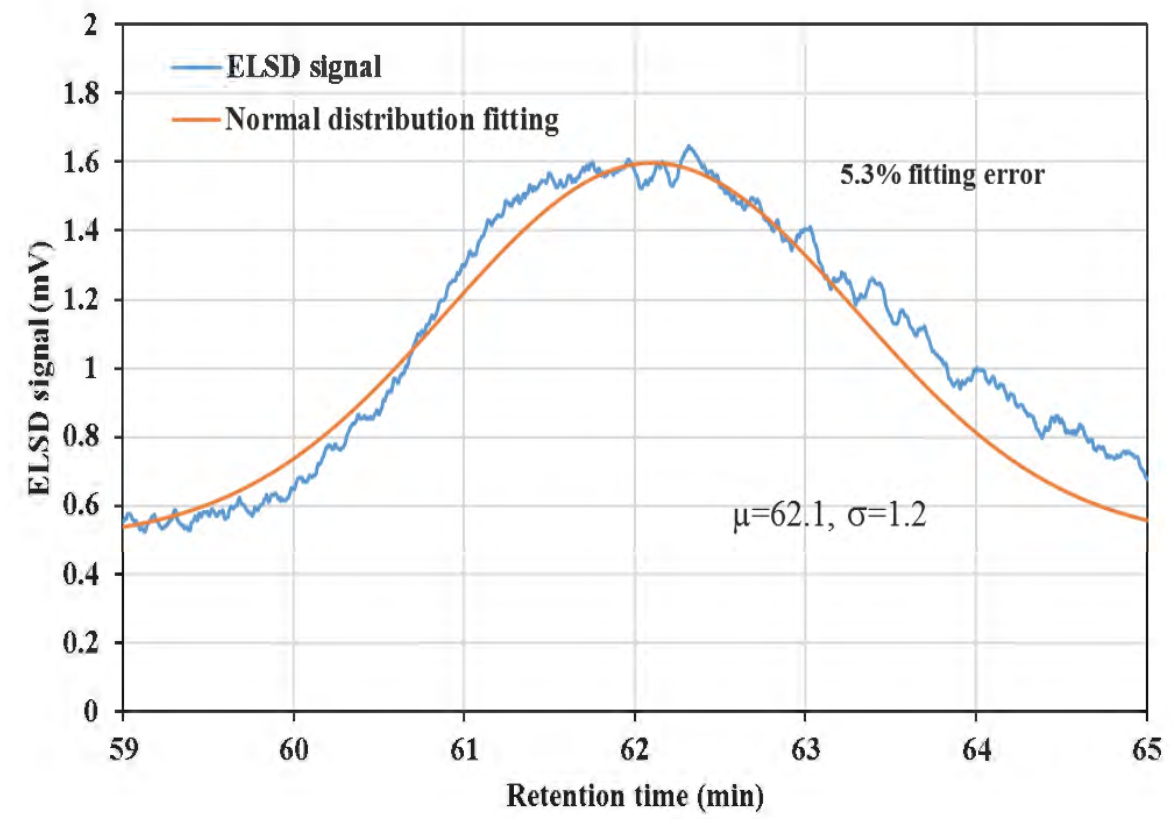

Figure 2. Normal distribution curve fitting of the ELSD response of the L38 signal

To distinguish each signal, the L38 signal was initially fit to a normal distribution curve and subtracted from the total signal, as shown in Figure 2. Then, the LB and IOS signals were obtained, and the area could be calculated by integration.

\subsubsection{Inhibiting the thermal degradation of L38}

The stability of L38 was detected by HPLC-ELSD, and L38 is a $\mathrm{C}_{13}$-alcohol polyethylene glycol ether carboxylic acid. The polyoxyethylene units degraded due to the presence of oxygen and the degradation could be inhibited by adding $0.2 \mathrm{~mol} / \mathrm{L}$ sodium sulfite $\left(\mathrm{Na}_{2} \mathrm{SO}_{3}\right)$ solution as an oxygen scavenger. The ELSD signal without and with sodium sulfite is shown in Figure 3. Without adding an oxygen scavenger, it was found that L38 degraded under an oxidization environment. For this reason, all static adsorption experiments of $\mathrm{L} 38$ under $80^{\circ} \mathrm{C}$ include $0.2 \mathrm{~mol} / \mathrm{L}$ sodium sulfite. 


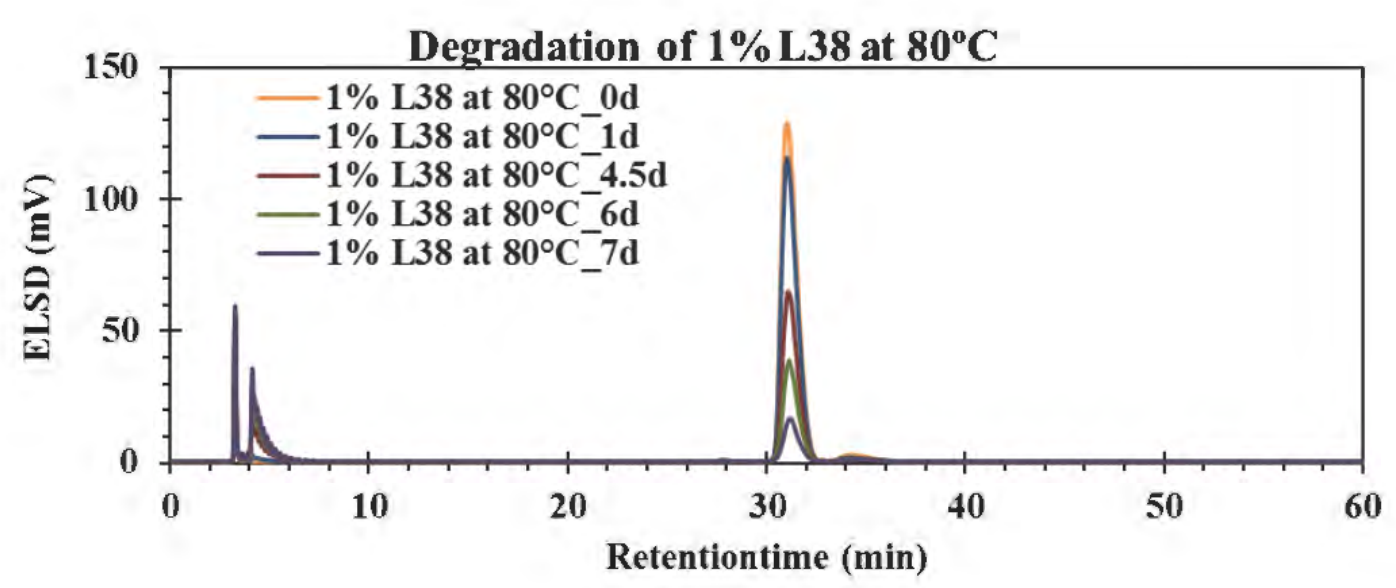

(a)

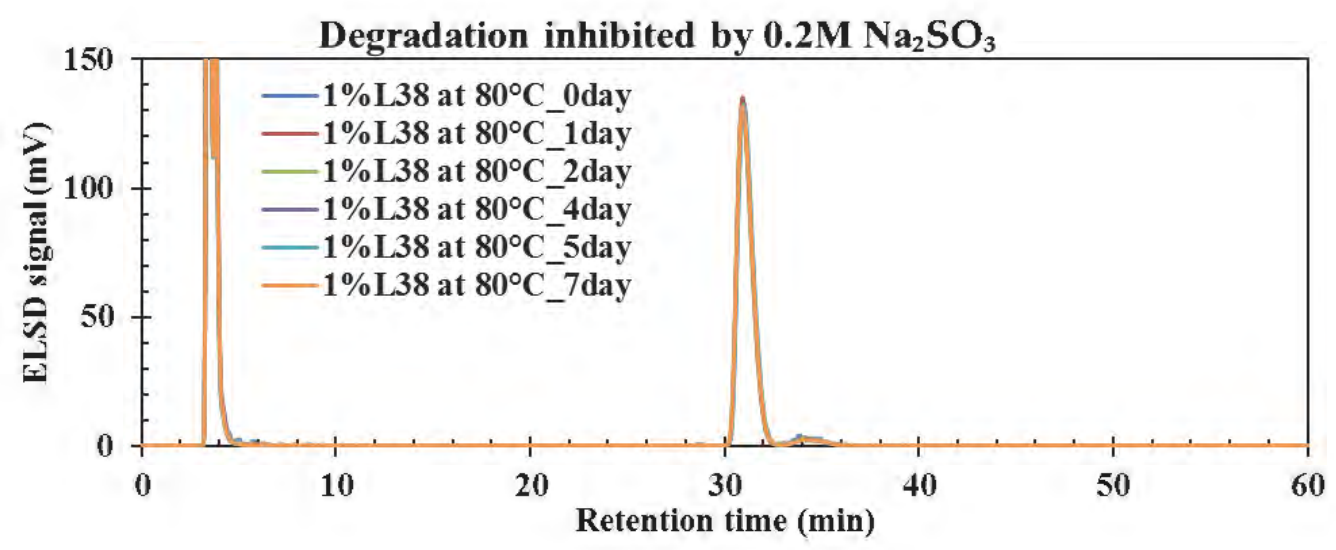

(b)

Figure 3. (a) Thermal degradation of a 1\% L38 solution and (b) inhibition of $1 \%$ L38 degradation using $0.2 \mathrm{M}$ sodium sulfite at $80^{\circ} \mathrm{C}$.

\subsubsection{Static adsorption}

The surfactant and mineral were loaded in a $30 \mathrm{~mL}$ glass tube and placed in an orbital shaker (Eberbach Corporation, Model No.6010) for 24 hours at a speed of $180 \mathrm{osc} / \mathrm{min}$. The supernatant was filtered through a $0.22 \mu \mathrm{m}$ filter before the HPLC-ELSD analysis. The adsorption amount was calculated using Equation 1. 


$$
\Gamma=\frac{\left(c_{i}-c_{e q}\right) \cdot m_{\text {surf }}}{m_{a b s} \cdot S_{B E T}}
$$

Where $c_{i}$ is the initial concentration of the surfactant (wt. \%); $c_{e q}$ is the equilibrium concentration of the surfactant (wt. \%); $m_{\text {surf }}$ denotes the mass of the surfactant solution (g), $m_{a b s}$ is the mass of the adsorbent (g), and $S_{B E T}$ represents the specific surface area $\left(\mathrm{m}^{2} / \mathrm{g}\right)$ of the adsorbent.

\section{Results and discussion}

\subsection{Static adsorption of individual surfactant solutions}
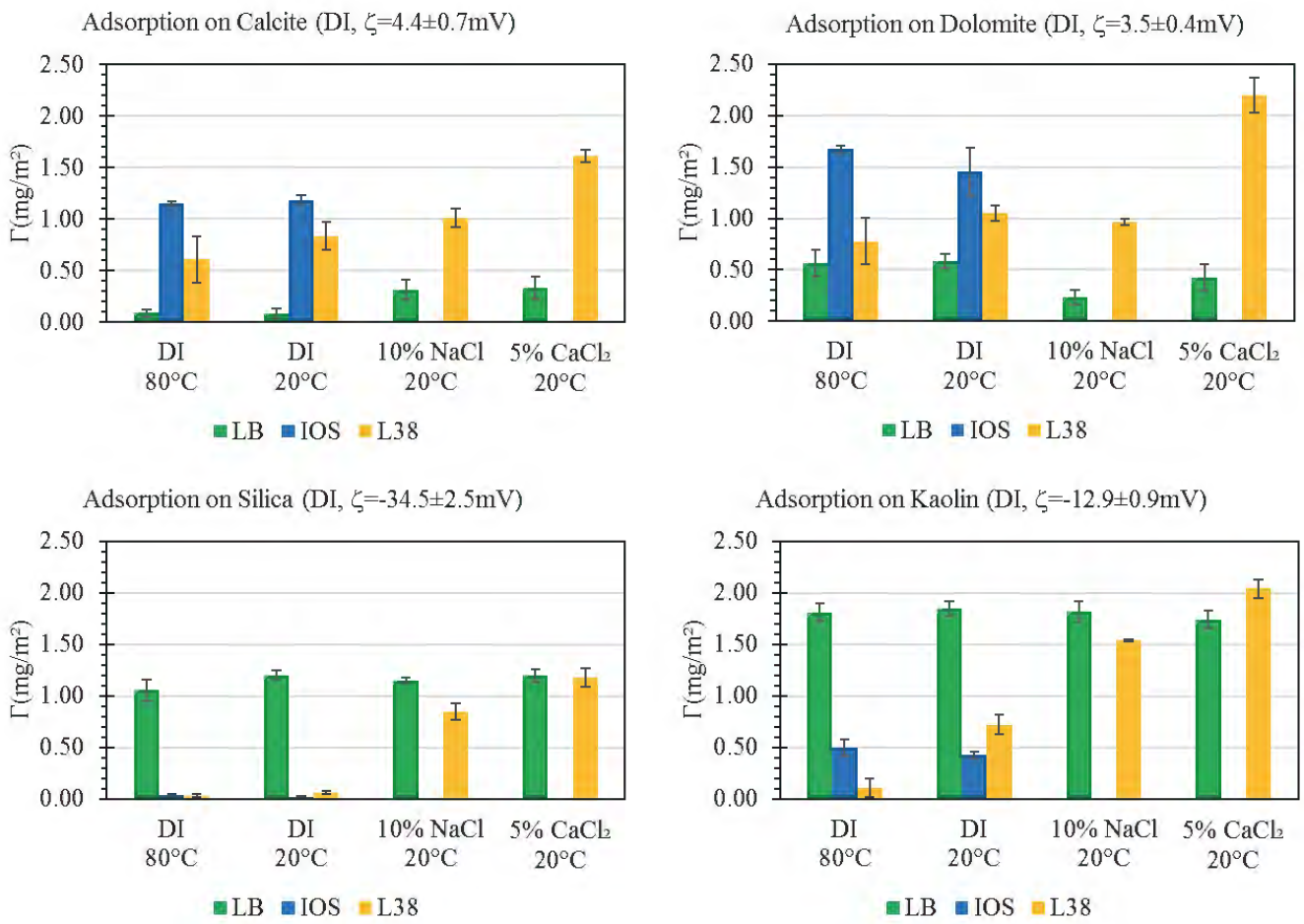

Figure 4. Adsorption of LB (green), IOS(blue), and L38(yellow) under the influence of various aqueous environments on different mineral surfaces.

The adsorption values of the individual surfactant components on the various mineral surfaces under various aqueous environments are shown in Figure 4. In particular, the effects of temperature, brine content, and cation valency were examined. The zeta potential shown was in $0.1 \mathrm{~mol} / \mathrm{L} \mathrm{NaCl}$ which is used as a reference value. Under the tested conditions, the LB surfactant exhibits a net positive charge; therefore, electrostatics indicate that LB adsorption is lowest on the 
pure calcite. However, since LB is a zwitterionic surfactant, it is thought to adsorb in a V-shape molecular configuration[27] on negative binding sites. With the increased salinity $\left(5 \% \mathrm{CaCl}_{2}\right.$ or $10 \% \mathrm{NaCl}$ ), the electric double-layer repulsion on the calcite surface decreased, leading to a slightly higher adsorption of LB on the calcite. The adsorption of LB on dolomite was relatively low at $0.59 \mathrm{mg} / \mathrm{m}^{2}$. The increased adsorption of LB on dolomite compared to calcite was due to impurities such as silica. Previously, Ma et al. showed that as low as a $1 \%$ silica impurity in dolomite resulted in significant adsorption of cationic surfactants[28]. Unlike the calcite case, adding salinity decreases the LB adsorption, which is likely due to the screening of the negatively charged impurity sites on the dolomite surface by the cationic ions in the brine solution. There was high adsorption of LB on the silica and kaolin surfaces, which are both negatively charged. In these cases, the salinity did not significantly alter the adsorption values. Kaolin exhibited the highest LB adsorption, and others have shown that kaolin has both positive and negative charge sites[29], which can interact with zwitterionic surfactants. In all cases, increasing the temperature from room temperature to $80^{\circ} \mathrm{C}$ had a negligible effect on adsorption of LB and IOS in DI water solutions.

The adsorption of IOS was not tested in high salinity brine due to its precipitation. IOS is an anionic surfactant, so it is expected to have the opposite results compared to LB. For the positively charged minerals, dolomite and calcite, high adsorption was observed due to electrostatic attraction. For the silica surface, IOS adsorption was negligible (below $0.05 \mathrm{mg} / \mathrm{m}^{2}$ ) as a result of the strong surface repulsion. For the kaolin interface, the IOS adsorption was higher than that on the silica due to kaolin containing both positively and negatively charged sites.

L38 is also an anionic surfactant that follows a trend similar to IOS in that the highest adsorption was observed on the calcite and dolomite surfaces due to electrostatic attraction. However, in the solution of $5 \% \mathrm{CaCl}_{2}$, the adsorption of $\mathrm{L} 38$ increased significantly (for all the minerals investigated), which was caused by the increased positive zeta potential of the mineral surface, as shown in Figure 5. The zeta potential of mineral without electrolyte or with high concentration of electrolyte was not performed due to experimental limitation. In general, for all the minerals investigated, the zeta potential increases with the concentration increase of $\mathrm{CaCl}_{2}$ and $\mathrm{NaCl}$. The zeta potential of Kaolin, however, decreases with the increase of $\mathrm{CaCl}_{2}$. 
Of particular interest is the L38 adsorption onto the silica and kaolin surfaces, which deviated from the trends observed with IOS. L38 had higher adsorption on silica and kaolin at $20^{\circ} \mathrm{C}$ and DI condition compared to IOS. This result may be due to hydrogen bonding between the EO group in L38 and the hydroxyl groups on silica and kaolin.

Effect of electrolyte on the zeta potential of Calcite

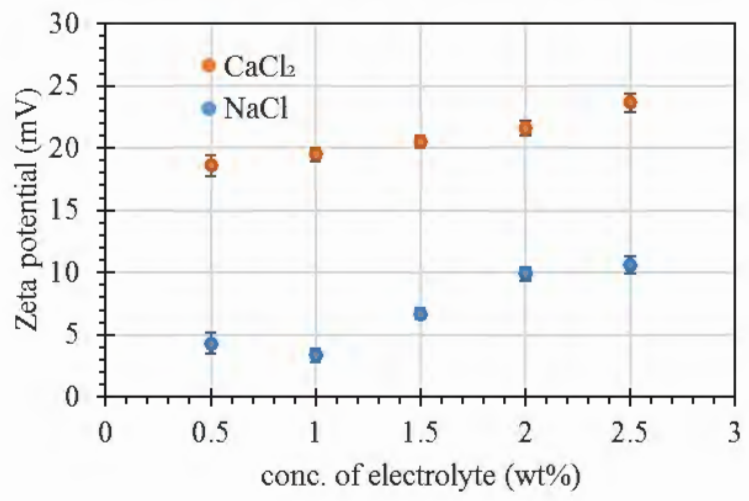

Effect of electrolyte on the zeta potential of Silica

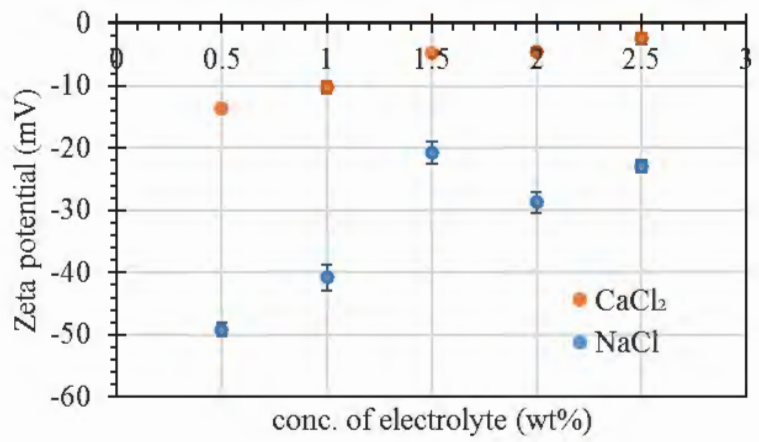

Effect of electrolyte on the zeta potential of dolomite

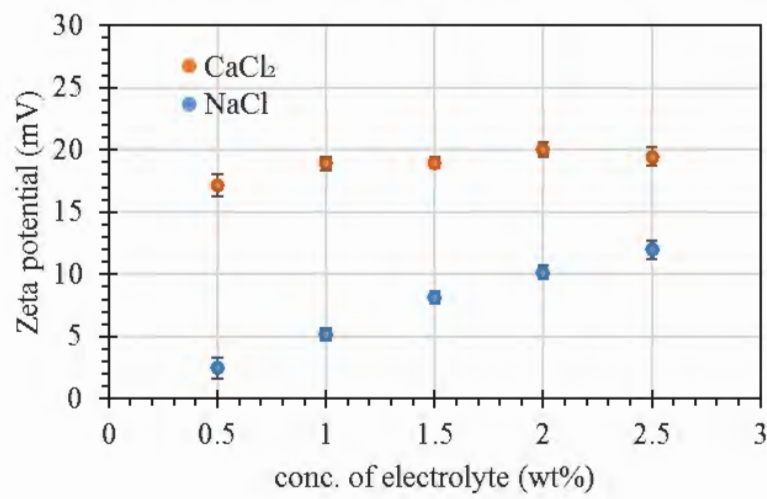

Effect of electrolyte on the zeta potential of Kaolin

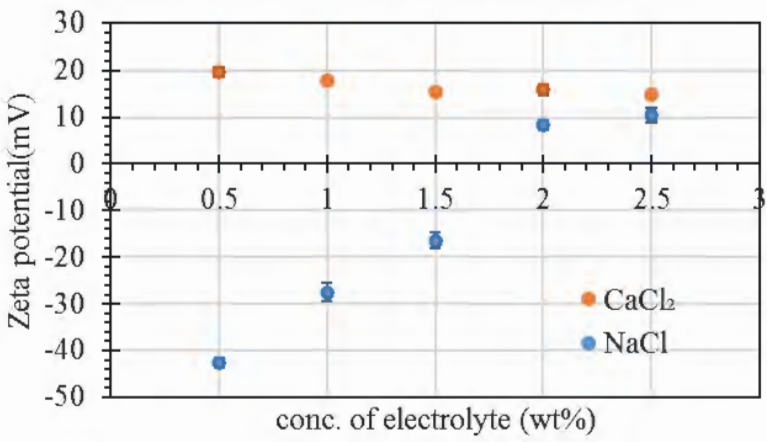

Figure 5. Effect of electrolyte and its concentration on the zeta potential of different minerals at $20^{\circ} \mathrm{C}$.

For adsorption under high temperatures, all surfactant solution was prepared in a $0.2 \mathrm{M} \mathrm{Na}_{2} \mathrm{SO}_{3}$ solution, which can effectively inhibit decomposition of L38 under high-temperature conditions, as described previously. The adsorption of L38 on different mineral surfaces was the lowest when the adsorption was conducted at high temperatures with sodium sulfite present. The reason for this adsorption reduction was the fact that sulfite can react with oxygen and generate sulfate, which is the potential determining ion and can decrease the surface potential to negative values for the 
positive binding sites. This will lead to the electrostatic repulsion of the mineral surface and the negative hydrophilic head group of the L38 surfactant, which is the reason for low adsorption at high temperatures.

\subsection{Adsorption of a two-surfactant blend on carbonates}

This work is motivated by understanding surfactant adsorption from a blended solution. Initially, blends of two surfactants were considered: LB + IOS and LB + L38. Since LB is cationic at the tested conditions, it more readily forms surfactant complexes with anionic surfactants such as IOS or L38.

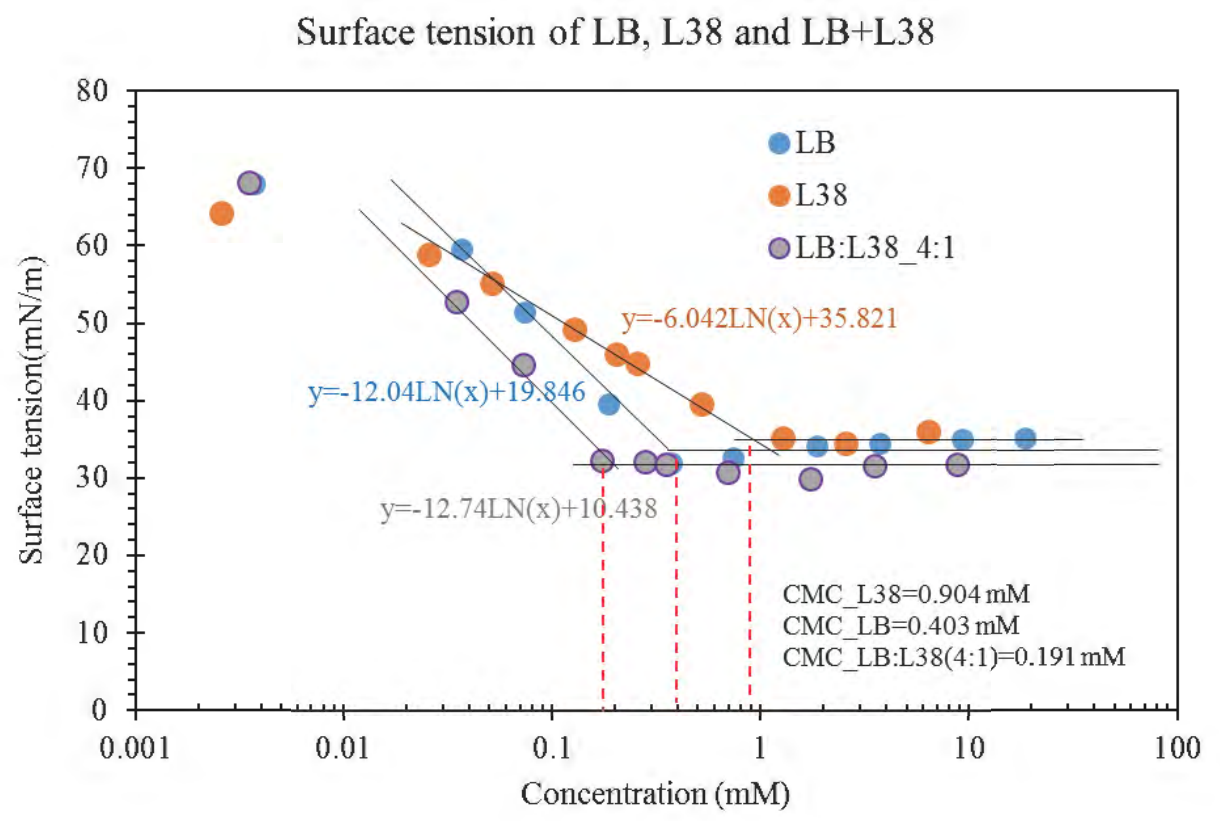

Figure 6. Surface tension of LB, L38, and LB+L38 (4:1 by mass ratio) as a function of concentration.

The surface tension measurements of the mixed surfactant systems (LB+L38) is shown in Figure 6, and the corresponding critical micelle concentration (CMC) values are calculated. The molecular interaction parameter $\beta^{M}$ for a mixed micelle formations by two different surfactants is calculated by the following equations[30]. 


$$
\begin{gathered}
\frac{\left(X_{1}^{M}\right)^{2} \ln \frac{\alpha C_{12}^{M}}{X_{1}^{M} C_{1}^{M}}}{\left(1-X_{1}^{M}\right)^{2} \ln \frac{(1-\alpha) C_{12}^{M}}{\left(1-X_{1}^{M}\right) C_{2}^{M}}}=1 \\
\beta^{M}=\frac{\ln \frac{\alpha C_{12}^{M}}{X_{1}^{M} C_{1}^{M}}}{\left(1-X_{1}^{M}\right)^{2}}
\end{gathered}
$$

Equation 3

where $\alpha$ is the molar fraction of surfactant 1 in the solution phase; $X_{1}^{M}$ is the molar fraction of surfactant 1 in the mixed micelle; $C_{1}^{M}, C_{2}^{M}$ and $C_{12}^{M}$ are CMCs of individual surfactant 1,2 , and their mixture at a given value of $\alpha$, respectively.

The calculated interaction parameters of LB and L38 system are $X_{1}^{M}=0.51$ and $\beta^{M}=-5.5$. A negative $\beta^{M}$ for $\mathrm{LB}+\mathrm{L} 38$ system indicated strong intermolecular attraction between the surfactant molecules. Additionally, the $\mathrm{CMC}$ of the $\mathrm{LB}+\mathrm{L} 38$ blend is below the $\mathrm{CMC}$ values of the individual surfactants, as listed in Figure 6, which is also characteristic of surfactant synergy.

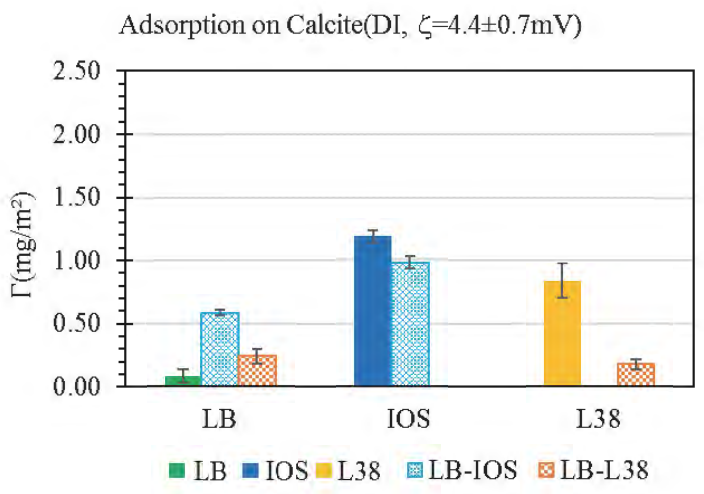

(a)

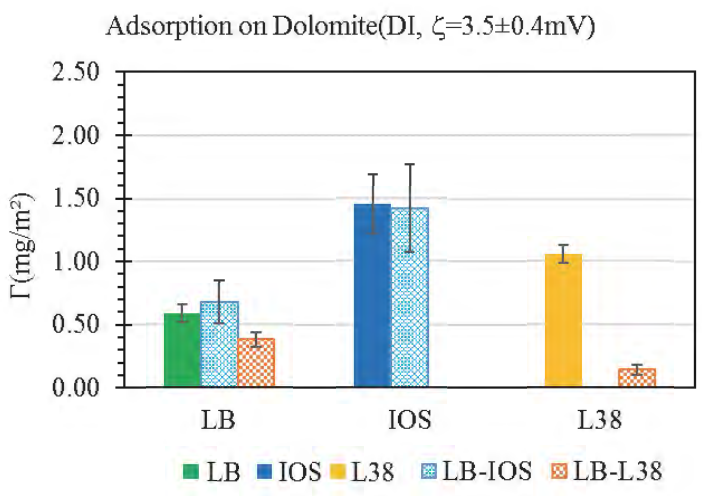

(b)

Figure 7. Comparison of the static adsorption of individual surfactants with the adsorption of blended mixtures of LB-IOS (0.4 wt $\%$ LB $+0.6 \mathrm{wt} \%$ IOS) and LB-L38 (0.4 wt\% LB $+0.1 \mathrm{wt} \%$ L38) on (a) calcite and (b) dolomite minerals in DI water at $20^{\circ} \mathrm{C}$. 
For the $0.6 \mathrm{wt} \%$ IOS $+0.4 \mathrm{wt} \%$ LB blend formulation, the IOS complexes with LB. Adsorption from blends of LB-IOS was compared to the single surfactant adsorption on calcite (Figure 7(a)) and dolomite (Figure 7 (b)). The adsorption of IOS, when blended with LB, did not significantly change compared to the IOS alone, while the LB adsorption values increased significantly[31] on calcite and increased slightly on dolomite when blended. The total adsorption of the blend of IOS and LB was $1.56 \mathrm{mg} / \mathrm{m}^{2}$, which is higher when compared to $1.27 \mathrm{mg} / \mathrm{m}^{2}$, which is the sum of the individual IOS and LB adsorption on calcite. Similarly, the total adsorption of IOS and LB when blended was $2.10 \mathrm{mg} / \mathrm{m}^{2}$, while the sum of the individual surfactants was $2.05 \mathrm{mg} / \mathrm{m}^{2}$ on dolomite.

The LB-L38 adsorption behavior significantly differs when compared to the LB-IOS blend. For the $0.1 \mathrm{wt} \% \mathrm{~L} 38+0.4 \mathrm{wt} \% \mathrm{LB}$ blend formulation, the L38 also complexes with LB. As with the IOS, adsorption from blends of LB-L38 was compared to the single surfactant adsorption on calcite (Figure 7(a)) and dolomite (Figure 7 (b)) minerals. Unlike IOS, the adsorption of L38 significantly decreased, while LB adsorption slightly increased on calcite and decreased on dolomite when blended compared to their unmixed state. The total adsorption of the blend of L38 and LB was $0.41 \mathrm{mg} / \mathrm{m}^{2}$, while the sum of the individual surfactant adsorption was $0.92 \mathrm{mg} / \mathrm{m}^{2}$ on the calcite surface. Additionally, the total adsorption of the blend of L38 and LB was $0.52 \mathrm{mg} / \mathrm{m}^{2}$ versus the sum of the individual surfactant adsorption is $1.64 \mathrm{mg} / \mathrm{m}^{2}$ on the dolomite.

These test results may be explained by the fact that the surfactant blend adsorbs to the positive binding sites of the carbonate surfaces as surfactant complexes, as illustrated in Figure 8. The lauryl betaine adsorbed on the carbonate surface via its carboxylate head, while the quaternary ammonium cations formed surfactant complexes with the IOS sulfonate anion head. The IOS and IOS-LB surfactant complexes compete for positive sites on the surface. In the case of the LB-L38 blends, the quantity of LB molecules is in significant excess. Therefore, it has preferential adsorption compared with the L38-LB surfactant complexes, resulting in a reduction of L38 adsorption. It is also hypothesized that L38 surfactant may preferentially partition into the LB micelles, which decreases its adsorption on carbonate surface. These results highlight the importance of considering surfactant ratio when designing blended surfactant systems for application involving surfactant adsorption. 
The test results indicate that anionic/cationic mixtures can be used to increase adsorption of a surfactant having the same sign of charge as the solid surface in some applications when such an increase may be desirable. It can be achieved by using a mixture of the surfactant of interest with a surfactant having charge of the opposite sign. Previous reports have examined anionic sodium dodecyl sulfate (SDS) at a concentration above its critical micelle concentration (CMC) adsorbed on a positively-charged alumina surface[31]. When a small amount of $\mathrm{C} 12$ pyridinium chloride is added to the solution, the adsorption of SDS remained constant while the adsorption of the cationic surfactant increased, as its concentration in aqueous solution after equilibration increases. The total amount of adsorbed surfactant and the number of surfactant molecules per unit area both increase, but the net charge of adsorbed surfactant remains negative on the positive surface for the range of conditions studied. Our LB-IOS system with calcite is similar. When IOS is in excess, LB adsorption from the binary mixture is significantly greater than for LB alone. The total surfactant adsorption increases, where the adsorbed layer is likely a mixture of IOS and surfactant complexes in comparable amounts.

In the case of the LB-L38 system, adsorption of LB exceeds that for the individual LB system. Thus, even when LB is in excess, in contrast to the example and LB-IOS system, enhanced adsorption of LB is observed. However, the increase in LB adsorption is much less than in the LBIOS system.
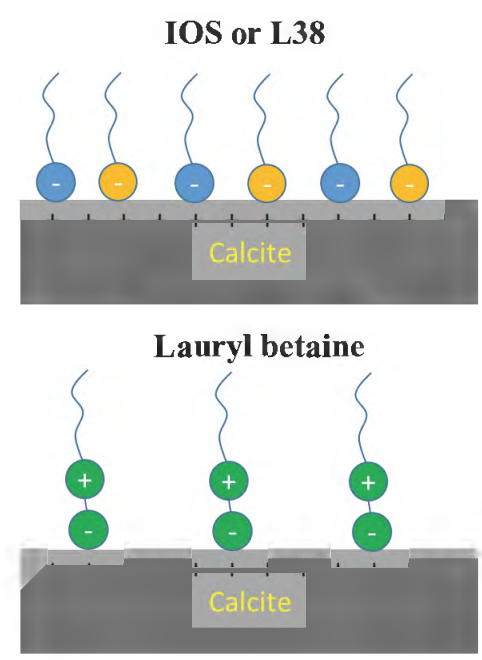
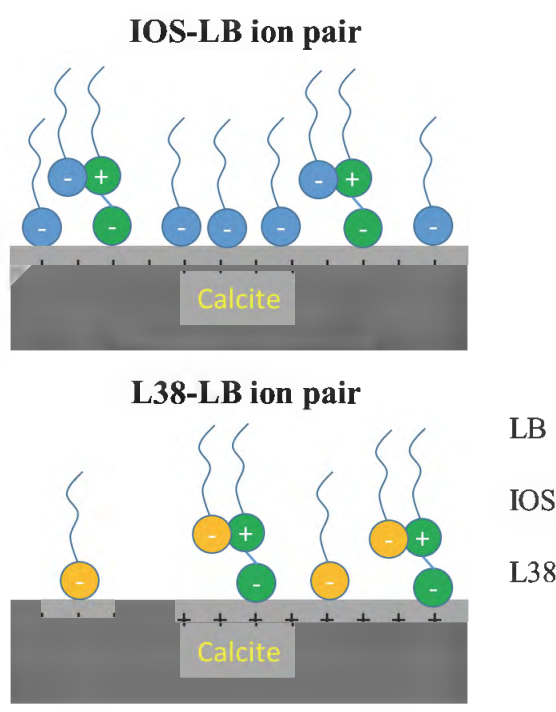

Figure 8. Illustration of adsorption mechanism of surfactants in their pure form and from blends on carbonate surfaces. 
An example of surfactant desorption by this mechanism is the work of Standnes and Austad[32]. They injected a cationic surfactant solution well above the CMC to form surfactant complexes with and desorb anionic naphthenate molecules, which had adsorbed from crude oil onto positively charged carbonate surfaces. They proposed that the surfactant complexes became part of the micelles, i.e., the introduction of anionic naphthenate molecules into the micelles would reduce electrostatic repulsion among the cationic surfactant molecules. The initially oil-wet carbonate surface became water wet, indication desorption of the naphthenate molecules. A related paper [33] disclosed that $\mathrm{C}_{8} \mathrm{TAB}$, an amine oxide, and a betaine could convert kaolinite with adsorbed naphthenate from oil wet to water wet, probably by forming surfactant complexes which desorbed. No adsorption measurements were made, just wettability was determined by whether most of the kaolinite particles present resided in aqueous or oil phase. In our manuscript, the LB/L38 with LB in excess is an example of this mechanism because adsorption of L38 on calcite is decreased by a factor of $\sim 4$ compared to that for L38 alone.

To better understand surfactant complexes adsorption in the presence of electrolytes, adsorption experiments for the LB-L38 blend was conducted in $5 \% \mathrm{CaCl}_{2}$ at room temperature. As shown in Figure 9, it was found that the adsorption of LB and L38 as single surfactant solutions were 0.33 $\mathrm{mg} / \mathrm{m}^{2}$ and $1.61 \mathrm{mg} / \mathrm{m}^{2}$, respectively on calcite and $0.43 \mathrm{mg} / \mathrm{m}^{2}$ and $2.20 \mathrm{mg} / \mathrm{m}^{2}$, respectively on dolomite. These values are different when compared to that in DI water, because of greater attraction due to higher surface potential and surface charge for L38 but less repulsion due to higher ionic strength for LB. Furthermore, the L38 adsorption significantly decreased when blended when compared to the surfactant alone in the brine solution. These test results match those found with the DI water system, indicating that when L38 complexes with LB as surfactant complexes, its adsorption significantly decreases due to the partitioning of L38 into micelles. 


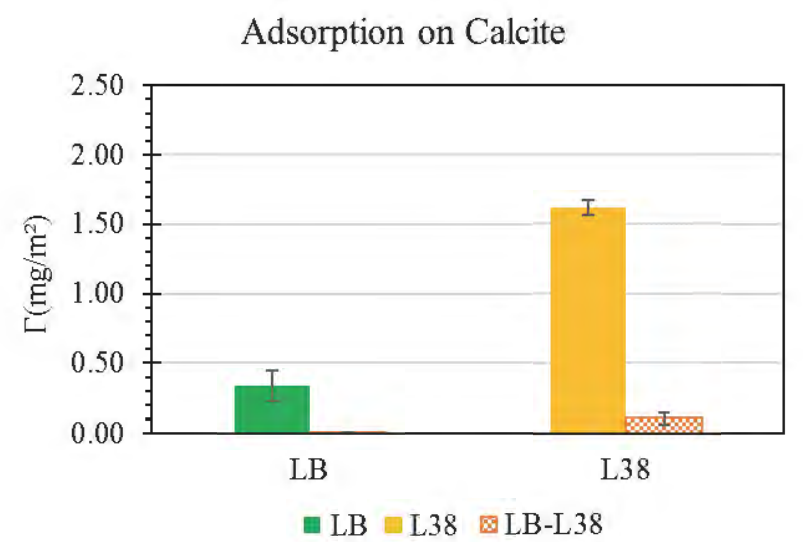

(a)

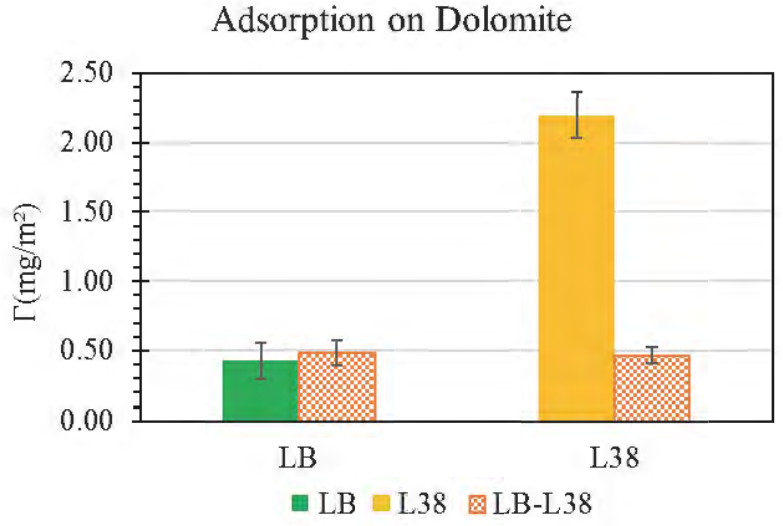

(b)

Figure 9. Adsorption of $0.1 \mathrm{wt} \% \mathrm{~L} 38+0.4 \mathrm{wt} \% \mathrm{LB}$ in $5 \mathrm{wt} \% \mathrm{CaCl}_{2}$ on

(a) calcite and (b) dolomite at $20^{\circ} \mathrm{C}$.

\subsection{Adsorption of a three-surfactant blend on carbonates}

For the three-surfactant blended system, $0.1 \mathrm{wt} \% \mathrm{~L} 38+0.6 \mathrm{wt} \% \mathrm{IOS}+0.4 \mathrm{wt} \% \mathrm{LB}$ in DI water at $20^{\circ} \mathrm{C}$, the LB can form surfactant complexes with either the IOS or the L38. Figure 10 compares the adsorption results on each surfactant in a blended system with those reported for the single surfactant and 3-surfactant systems in DI water for calcite and dolomite, respectively. The adsorption of IOS $\left(0.79 \mathrm{mg} / \mathrm{m}^{2}\right.$ on calcite and $1.15 \mathrm{mg} / \mathrm{m}^{2}$ on dolomite $)$ in the LB-IOS-L38 blend decreased when compared to the IOS-LB surfactant blend $\left(0.98 \mathrm{mg} / \mathrm{m}^{2}\right.$ on calcite and $1.42 \mathrm{mg} / \mathrm{m}^{2}$ on dolomite). The adsorption of $\mathrm{L} 38\left(0.08 \mathrm{mg} / \mathrm{m}^{2}\right.$ on calcite and $0.23 \mathrm{mg} / \mathrm{m}^{2}$ on dolomite $)$ in the IOS-LB-L38 blend remained relatively unchanged when compared to the L38-LB surfactant blend $\left(0.17 \mathrm{mg} / \mathrm{m}^{2}\right.$ on calcite and $0.14 \mathrm{mg} / \mathrm{m}^{2}$ on dolomite $)$. Additionally, the adsorption of $\mathrm{LB}(0.42$ $\mathrm{mg} / \mathrm{m}^{2}$ on calcite and $0.59 \mathrm{mg} / \mathrm{m}^{2}$ on dolomite) in the IOS-LB-L38 blend remained relatively unchanged when compared to the LB-IOS blend $\left(0.58 \mathrm{mg} / \mathrm{m}^{2}\right.$ on calcite and $0.68 \mathrm{mg} / \mathrm{m}^{2}$ on dolomite) but was higher when compared to the LB-L38 blend $\left(0.24 \mathrm{mg} / \mathrm{m}^{2}\right.$ on calcite and 0.38 $\mathrm{mg} / \mathrm{m}^{2}$ on dolomite). These test results also indicate that IOS and LB-IOS surfactant complexes preferentially adsorb onto carbonate surfaces when compared to the LB-L38 surfactant complexes at least preferentially compared to partitioning into micelles. 
Surfactant L38 adsorption from a ternary blend on calcite in DI water (shown in Figure 10) is similar to that of binary LB-L38 (shown in Figure 7). This is not surprising since L38 is only about $9 \%$ of the overall blend. Nevertheless, the approximately 8-fold decrease in L38 adsorption compared to individual surfactant adsorption could indicate that a greater fraction of L38, when compared to IOS, complexes into surfactant complexes. Furthermore, these complexes are mainly in micelles, as in the LB-L38 binary mixture, which indicates that L38 may have a greater tendency than IOS to stay as a surfactant complex instead of adsorbed onto the mineral surface. This could be explained by the fact that the EO chain on L38 prefers to be immersed in water rather than adsorbed onto the calcite surface, indicating that surfactant structure also influences surface adsorption.

Furthermore, as shown in Figure 10, LB-IOS-L38 adsorption in a brine led to higher adsorption of all three surfactants due to increase in the positive zeta potential of the carbonate surfaces. The main reason for the decrease in total adsorption is the much lower L38 adsorption when blended. 

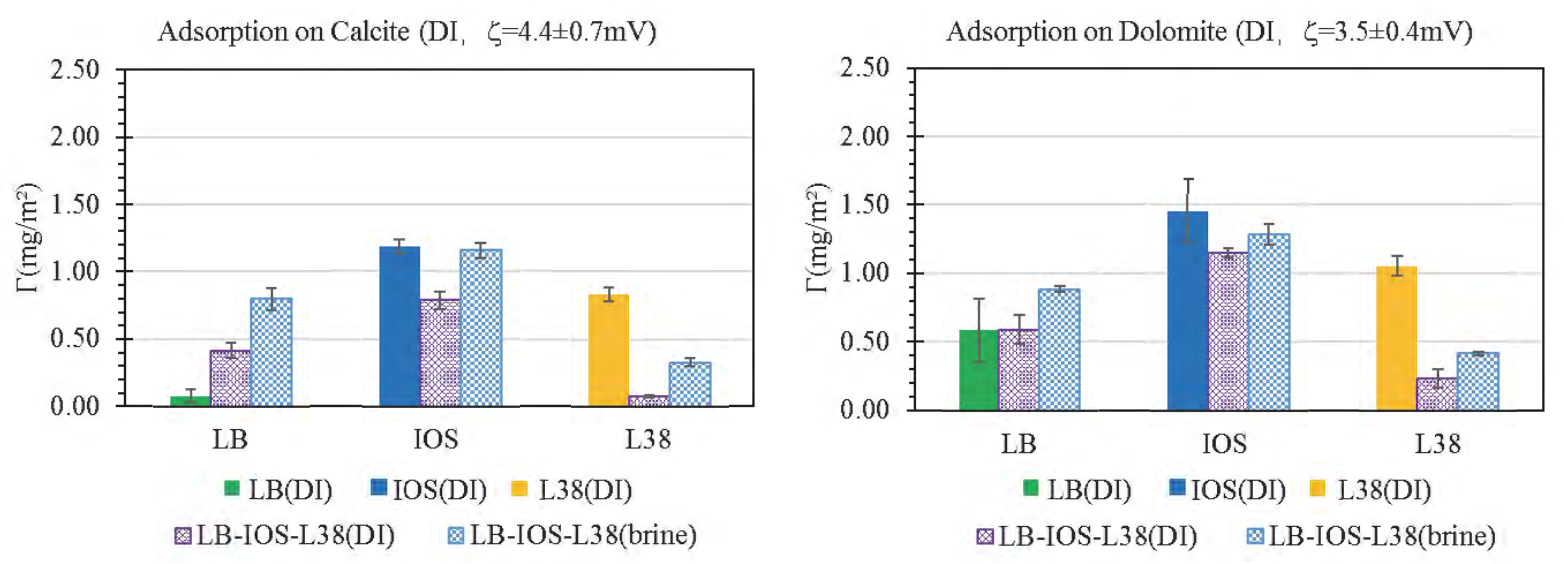

Figure 10. Adsorption of $0.1 \% \mathrm{~L} 38+0.6 \% \mathrm{IOS}+0.4 \% \mathrm{LB}$ on calcite and dolomite in DI or brine environments, $20^{\circ} \mathrm{C}$.

\section{Conclusions}

Surfactant blends with strong charge interactions that form surfactant complexes are difficult to analyze by standard titration methods[13] [28] [34]. However, these surfactant blends can be separated by chromatographic separation with specific coated columns. Changing the properties of the mobile phase tunes the properties of the surfactant molecules, resulting in a unique chromatographic separation. A significant contribution of this manuscript is the development of HPLC-ELSD as an analytical method to analyze surfactant complexes adsorption.

The surfactant blend studied in this manuscript was an LB/IOS/L38 solution that has successfully been used previously for EOR[18] [21]. The main finding was that LB adsorption increased when blended with either IOS or L38 due to surfactant complexes complexation on pure calcite surface. At least three factors were found to influence adsorption in these systems. First, the formation of surfactant complexes or, more generally, anionic/cationic surfactant complexes; second, the electrostatic interaction between the surfactants and solid surfaces; and lastly, the partitioning of surfactant complexes between the surface and micelles.

The HPLC-ELSD method developed in this study could be used for surface phenomenon analysis of complex surfactant systems. Specifically, it could be used for designing surfactant formulations such as anionic/cationic mixtures to decrease adsorption of a surfactant having the opposite sign 
of charge as the solid surface. If it is desired to minimize adsorption from solution or to desorb a surfactant having charge opposite in sign to that of the solid surface, one can prepare an aqueous solution having an excess of a surfactant having charge of the same sign as the solid surface. If one wishes to increase adsorption of a surfactant having the same sign of charge as the solid, it is best to have the surfactant of opposite charge in excess in the aqueous solution.

\section{Acknowledgements}

The authors acknowledge the Processes in Porous Media Consortium of Rice University.

\section{References}

[1] G.J. Hirasaki, C.A. Miller, M. Puerto, Recent Advances in Surfactant EOR, in: Society of Petroleum Engineers, 2008. doi:10.2118/115386-MS.

[2] M.J. Rosen, H. Wang, P. Shen, Y. Zhu, Ultralow Interfacial Tension for Enhanced Oil Recovery at Very Low Surfactant Concentrations, Langmuir. 21 (2005) 3749-3756. doi:10.1021/la0400959.

[3] W. Qiao, Y. Cui, Y. Zhu, H. Cai, Dynamic interfacial tension behaviors between Guerbet betaine surfactants solution and Daqing crude oil, Fuel. 102 (2012) 746-750. doi:10.1016/j.fuel.2012.05.046.

[4] W. Qiao, J. Li, Y. Zhu, H. Cai, Interfacial tension behavior of double long-chain 1,3,5-triazine surfactants for enhanced oil recovery, Fuel. 96 (2012) 220-225. doi:10.1016/j.fuel.2012.01.014.

[5] G. Jian, Q. Hou, S. Chen, D. Wang, Y. Luo, Z. Wang, Y. Zhu, Comparative Study of Extensional Viscoelasticity Properties of Liquid Films and Stability of Bulk Foams, J. Dispers. Sci. Technol. 34 (2013) 1382-1391. doi:10.1080/01932691.2012.749182.

[6] G. Jian, Q. Hou, Y. Zhu, Stability of Polymer and Surfactant Mixture Enhanced Foams in the Presence of Oil Under Static and Dynamic Conditions, J. Dispers. Sci. Technol. 36 (2015) 477-488. doi:10.1080/01932691.2014.907539.

[7] S. Chen, G. Jian, Q. Hou, S. Gao, Y. Luo, Y. Zhu, W. Li, Effect of oil on the stability of polymer enhanced foams, Int. J. Oil Gas Coal Technol. (2013). http://www.inderscienceonline.com/doi/abs/10.1504/IJOGCT.2013.056809?journalCode=ijogct (accessed March 29, 2017).

[8] Y. Zhu, Q. Hou, G. Jian, D. Ma, Z. Wang, Current development and application of chemical combination flooding technique, Pet. Explor. Dev. 40 (2013) 96-103. doi:10.1016/S18763804(13)60009-9.

[9] Y. Zhu, Q. Hou, R. Weng, G. Jian, Y. Luo, J. Li, Recent Progress and Effects Analysis of Foam Flooding Field Tests in China, in: Society of Petroleum Engineers, 2013. doi:10.2118/165211-MS.

[10] G. Jian, M.C. Puerto, A. Wehowsky, P. Dong, K.P. Johnston, G.J. Hirasaki, S.L. Biswal, Static Adsorption of an Ethoxylated Nonionic Surfactant on Carbonate Minerals, Langmuir. 32 (2016) 10244-10252. doi:10.1021/acs.langmuir.6b01975.

[11] Y. Wang, J. Ge, G. Zhang, P. Jiang, W. Zhang, Y. Lin, Adsorption behavior of dodecyl hydroxypropyl sulfobetaine on limestone in high salinity water, RSC Adv. 5 (2015) 59738-59744. doi:10.1039/C5RA10694J.

[12] C. Dai, J. Zhao, L. Yan, M. Zhao, Adsorption behavior of cocamidopropyl betaine under conditions of high temperature and high salinity, J. Appl. Polym. Sci. 131 (2014) n/a-n/a. doi:10.1002/app.40424. 
[13] H. ShamsiJazeyi, R. Verduzco, G.J. Hirasaki, Reducing adsorption of anionic surfactant for enhanced oil recovery: Part I. Competitive adsorption mechanism, Colloids Surf. Physicochem. Eng. Asp. 453 (2014) 162-167. doi:10.1016/j.colsurfa.2013.10.042.

[14] Y. Li, W. Zhang, B. Kong, M. Puerto, X. Bao, O. Sha, Z. Shen, Y. Yang, Y. Liu, S. Gu, C. Miller, G.J. Hirasaki, Mixtures of Anionic/Cationic Surfactants: A New Approach for Enhanced Oil Recovery in Low-Salinity, High-Temperature Sandstone Reservoir, SPE J. 21 (2016) 1,164-1,177. doi:10.2118/169051-PA.

[15] Z.-Y. Liu, Z.-Q. Li, X.-W. Song, J.-C. Zhang, L. Zhang, L. Zhang, S. Zhao, Dynamic interfacial tensions of binary nonionic-anionic and nonionic surfactant mixtures at water-alkane interfaces, Fuel. 135 (2014) 91-98. doi:10.1016/j.fuel.2014.06.031.

[16] X.-M. Pei, J.-J. Yu, X. Hu, Z.-G. Cui, Performance of palmitoyl diglycol amide and its anionic and nonionic derivatives in reducing crude oil/water interfacial tension in absence of alkali, Colloids Surf. Physicochem. Eng. Asp. 444 (2014) 269-275. doi:10.1016/j.colsurfa.2013.12.068.

[17] S. Kumar, A. Mandal, Studies on interfacial behavior and wettability change phenomena by ionic and nonionic surfactants in presence of alkalis and salt for enhanced oil recovery, Appl. Surf. Sci. 372 (2016) 42-51. doi:10.1016/j.apsusc.2016.03.024.

[18] M. Puerto, J.L.L. Salinas, C.A. Miller, G. Hirasaki, Ultra-low-tension compositions and their use in enhanced oil recovery, US20150267104 A1, 2015. http://www.google.com/patents/US20150267104 (accessed March 29, 2017).

[19] R.F. Li, W. Yan, S. Liu, G. Hirasaki, C.A. Miller, Foam Mobility Control for Surfactant Enhanced Oil Recovery, SPE J. 15 (2010) 928-942. doi:10.2118/113910-PA.

[20] S.M. Szlendak, N.M. Nguyen, Q.P. Nguyen, Investigation of localized displacement phenomenon for Low-Tension-Gas (LTG) injection in tight formations, J. Pet. Sci. Eng. 142 (2016) 36-45. doi:10.1016/j.petrol.2016.01.042.

[21] P. Dong, M. Puerto, K. Ma, K. Mateen, G. Ren, G. Bourdarot, D. Morel, M. Bourrel, S.L. Biswal, G. Hirasaki, others, Low-Interfacial-Tension Foaming System for Enhanced Oil Recovery in Highly Heterogeneous/Fractured Carbonate Reservoirs, in: SPE Int. Conf. Oilfield Chem., Society of Petroleum Engineers, 2017. https://www.onepetro.org/conference-paper/SPE-184569-MS (accessed May 7, 2017).

[22] D.A. Nieto-Alvarez, L.S. Zamudio-Rivera, E.E. Luna-Rojero, D.I. Rodríguez-Otamendi, A. MarínLeón, R. Hernández-Altamirano, V.Y. Mena-Cervantes, T.E. Chávez-Miyauchi, Adsorption of Zwitterionic Surfactant on Limestone Measured with High-Performance Liquid Chromatography: Micelle-Vesicle Influence, Langmuir. 30 (2014) 12243-12249. doi:10.1021/la501945t.

[23] J.B. Wan, F.Q. Yang, S.P. Li, Y.T. Wang, X.M. Cui, Chemical characteristics for different parts of Panax notoginseng using pressurized liquid extraction and HPLC-ELSD, J. Pharm. Biomed. Anal. 41 (2006) 1596-1601. doi:10.1016/j.jpba.2006.01.058.

[24] A. Avalli, G. Contarini, Determination of phospholipids in dairy products by SPE/HPLC/ELSD, J. Chromatogr. A. 1071 (2005) 185-190. doi:10.1016/j.chroma.2005.01.072.

[25] X.-Y. Chai, S.-L. Li, P. Li, Quality evaluation of Flos Lonicerae through a simultaneous determination of seven saponins by HPLC with ELSD, J. Chromatogr. A. 1070 (2005) 43-48. doi:10.1016/j.chroma.2005.02.031.

[26] S.N. Kim, Y.W. Ha, H. Shin, S.H. Son, S.J. Wu, Y.S. Kim, Simultaneous quantification of 14 ginsenosides in Panax ginseng C.A. Meyer (Korean red ginseng) by HPLC-ELSD and its application to quality control, J. Pharm. Biomed. Anal. 45 (2007) 164-170. doi:10.1016/j.jpba.2007.05.001.

[27] N. Li, G. Zhang, J. Ge, J. Luchao, Z. Jianqiang, D. Baodong, H. Pei, Adsorption Behavior of Betaine-Type Surfactant on Quartz Sand, Energy Fuels. 25 (2011) 4430-4437. doi:10.1021/ef200616b.

[28] K. Ma, L. Cui, Y. Dong, T. Wang, C. Da, G.J. Hirasaki, S.L. Biswal, Adsorption of cationic and anionic surfactants on natural and synthetic carbonate materials, J. Colloid Interface Sci. 408 (2013) 164-172. doi:10.1016/j.jcis.2013.07.006. 
[29] E. Tombácz, M. Szekeres, Surface charge heterogeneity of kaolinite in aqueous suspension in comparison with montmorillonite, Appl. Clay Sci. 34 (2006) 105-124. doi:10.1016/j.clay.2006.05.009.

[30] M.J. Rosen, Molecular Interactions and Synergism in Mixtures of Two Surfactants, in: Surfactants Interfacial Phenom., John Wiley \& Sons, Inc., 2004: pp. 379-414. doi:10.1002/0471670561.ch11.

[31] A. Upadhyaya, E.J. Acosta, J.F. Scamehorn, D.A. Sabatini, Adsorption of Anionic-Cationic Surfactant Mixtures on Metal oxide Surfaces, J. Surfactants Deterg. 10 (2007) 269-277. doi:10.1007/s11743-007-1045-3.

[32] D.C. Standnes, T. Austad, Wettability alteration in chalk, J. Pet. Sci. Eng. 28 (2000) 123-143. doi:10.1016/S0920-4105(00)00084-X.

[33] T. Jiang, G.J. Hirasaki, C.A. Miller, S. Ng, Wettability Alteration of Clay in Solid-Stabilized Emulsions, Energy Fuels. 25 (2011) 2551-2558. doi:10.1021/ef2000079.

[34] L. Cui, M. Puerto, J.L. López-Salinas, S.L. Biswal, G.J. Hirasaki, Improved methylene blue twophase titration method for determining cationic surfactant concentration in high-salinity brine, Anal. Chem. 86 (2014) 11055-11061. 